\title{
Smart Accident Detection and Switching of Traffic Signal
}

\author{
Kokila B, Sathayaseelan K, Pradeep C
}

\begin{abstract}
An accident is one of the major causes of unnatural and untimely death. This is one of the serious issues throughout the world. Most of the accidents occur due to vehicle factors, improper traffic management, and lack of timely help. With the increase in the number of vehicles, it may be little hard to keep away from such accidents on road. The main objective is to implement the new advancements in saving human lives by detecting the occurrence of the accident in a vehicle and by directing the ambulance to the accident location without time delay. Also by implementing smart traffic control system, the ambulance moves to medical centre in an effective way without any stall in the traffic signals. Automation of accident detection is implemented by sensor-based ambulance management with the smart traffic management system. It consists of Crash sensor and MEMS sensor for detecting the accident in the vehicle and $R F$ transmitter on the ambulance to communicate with the $R F$ Receiver located on the traffic signal. This helps the ambulance to cross the junction switching the signals from Red to Green when the signal is received by the ambulance.
\end{abstract}

Index Terms- Microcontroller, Accident System, Vehicle Section, Ambulance Service, Traffic signal, Global System for Mobile Communications (GSM), Global Positioning System (GPS).

\section{INTRODUCTION}

According to the 2015 Global Status Report on Road Safety [7], the total number of road accident deaths has risen to 1.25 million per year. In a current scenario, Most of the developing countries mainly has high risk of accidents due to lack of proper infrastructure for traffic management and accident management. Road traffic injuries, particularly among young people, are the leading cause of death and cost countries around $1-3 \%$ of gross domestic product [8]. Though the developing countries have been showing a wide range of improvement and advancement in transportation technology, due to improper traffic management road accidents are seen to be a major hazard. Delayed recovery of the victim to the nearby medical centre by an ambulance seems to have a higher death rate as compared to death rates of lack of quick medical assistance and the treatment in the medical centres.

Revised Manuscript Received on December 30, 2019.

* Correspondence Author

Kokila B, Department of CSE, Sri Ramakrishna Institute of Technology, Coimbatore, Email:kokila.cse@srit.org

Sathyaseelan K, Department of IT, Sri Ramakrishna Institute of Technology, Coimbatore, Email : sathyaseelan.it@srit.org

Pradeep C, Department of M\&H, Sri Ramakrishna Institute of Technology, Coimbatore, Email:pradeep.sh@srit.org

(c) The Authors. Published by Blue Eyes Intelligence Engineering and Sciences Publication (BEIESP). This is an open access article under the CC BY-NC-ND license (http://creativecommons.org/licenses/by-nc-nd/4.0/)
Secondly, Ambulance cannot reach the hospital in time and gets jam in the traffic signals. Due to the time delay, first aid cannot be given to the patient on time and more manpower is needed to control the traffic. This leads to the loss of human life.

Traffic management for emergency vehicle centralized or distributed approaches was proposed. In the Traffic management system, it automatically detects the accidents and dispatch and guides the nearest ambulance to the accident location with minimal delay involved.

This paper provides a solution by detecting and informing the occurrence of accident immediately to the nearby ambulance service MEMS and crash sensor are used to detect accidents. The accelerometer will monitor the forces of acceleration in 3 axes continuously. It will be considered as an incident if any sudden shift is observed in any of the axes. If accident is detected, microcontroller will send the location information to the ambulance service. The ambulance moves to the medical center without and traffic by effective traffic management system. The traffic signal is then controlled on the ambulance's path. When the ambulance reaches the traffic junction, when it passes from the transmitter to the receiver, the encoder converts the serial data to parallel data. If the signal is red, it will automatically turn green. In the receiver section, the decoder converts the parallel data when it is returned to serial data. This helps the ambulance to cross the traffic junction efficiently.

\section{RELATED WORKS}

In [1], an accident prevention system with vehicle identification to prevent the risk of accidents has been proposed. An accelerometer was used to measure the speed and the amount of tilting of the vehicle when it hits something. If the car's velocity exceeds or tilts the specified maximum speed for the road, an automatic warning will be given. In [2], a traffic light control system at a signalized intersection was designed to prevent incidents from causing large-scale traffic congestion. Strategies for the control of normal and emergency traffic light were formulated. It verifies the strategy's effectiveness through a simulation study that uses an extended CTM model to build the network of traffic.

In the paper [3], Smart ambulance has been described as an emergency rescue device. The emergency rescue program started to ensure that the ambulance would arrive on time at the accident site and enter the hospital as soon as possible to provide the patient with health services. It evaluated the road layout in three ways: rescue plan, monitoring of accidents and management of equipment. The system's reliability is discussed on the basis of travel time.

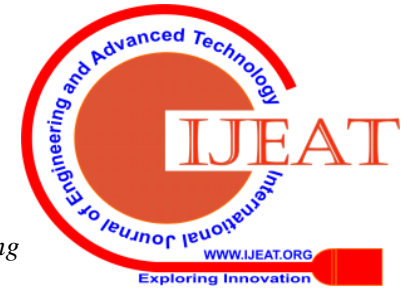




\section{Smart Accident Detection and Switching of Traffic Signal}

A mathematical model of travel time reliability is then established. It works on the gyroscope principle to detect the gravitational vertical stretcher. To drive the motor through the microcontroller, it is converted into pulse signals. To adjust the angle, the engine controls the ambulance to the full balance [4].

In the reference [6], they have designed the automation to control the traffic signals and the ambulance can cross the junction without any traffic delay. The ambulance reaches the hospital through the shortest path. Through GSM and GPS, it tracks and attains the accident spot and reaches the nearest hospital.

\section{PROPOSED METHOD}

The model has been proposed for accident detection and smart traffic management system to provide benefits to the people to avoid time loss and therefore saving the patient's life. The architecture of the proposed system is shown in the fig.1

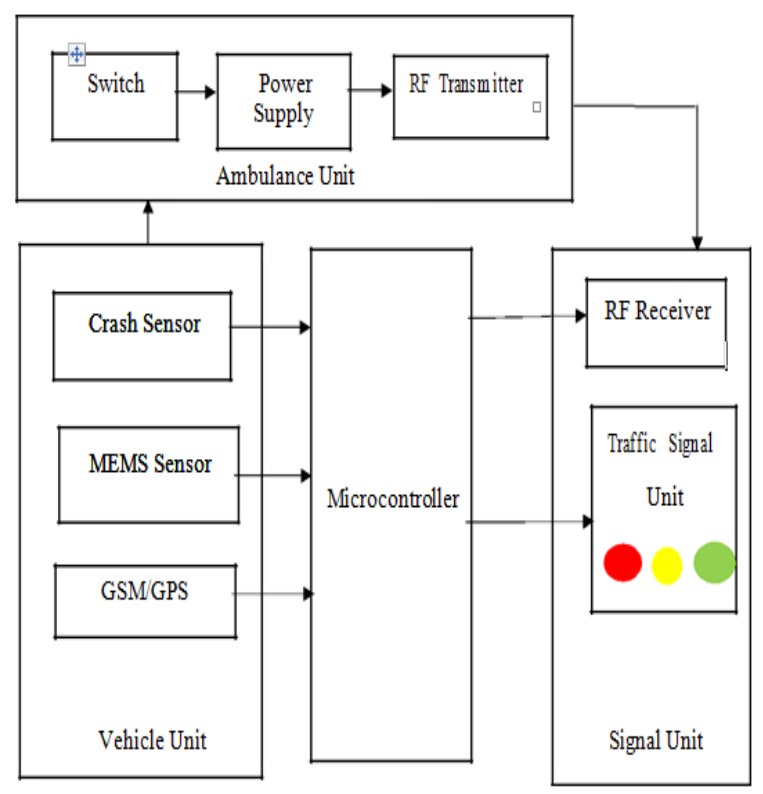

Fig.1 Proposed System Architecture

\section{A.Accident Detection}

The Proposed system detects the occurrence of the accident and identifies the seriousness of the injury of the victim/driver. The accident detection can be identified by using Crash sensor and MEMS Sensor. The Crash Sensor is a known as a microswitch, the miniature snap-movement switch. It is an electric switch that is actuated by way of little or no bodily force. The Sensors is placed in the vehicle which senses the accident and tracks the location of the accident by Global Positioning System (GPS).

A MEMS magnetic discipline sensor is a small-scale micro electro mechanical system (MEMS) which helps to detect and measure magnetic fields (Magnetometer). The location spot of the accident is sent to the ambulance service through GSM (Global System for Mobile Communication). GSM is a globally established fashionable for digital mobile conversation. A wi-fi modem behaves like a dial-up modem. It transmits and receives records over GPRS, making video calls and SMS module is used for sending SMS. The emergency unit of the medical centre searches for the ambulance which is nearby the accident spot and sends the ambulance to the accident location.

\section{B. Ambulance Section}

The ambulance driver thus receives the message and reaches the accident spot and takes the patient to the nearby medical Centre. An RF module (radio frequency module) is a small digital tool used to transmit and/or get hold of radio alerts among devices. The RF Transmitter is placed on the ambulance which transmits the signal to RF receiver located in the traffic Signal.

\section{Smart Traffic control}

If the ambulance reaches the traffic junction, the encoder converts the serial data into parallel data when it passes from the transmitter to the receiver [7]. The decoder in the receiver section converts the parallel data into serial data when it is sent back. The traffic signal is controlled when the receiver acquires the signal on the path of the ambulance. Though the signal is red, it switches the signal to green automatically. This helps the ambulance to cross the traffic junction as soon as possible without delay.

\section{EXPERIMENTAL RESULT}

The accident detection can be identified by the sensors such as Crash sensor and MEMS sensor. The Crash sensor is fitted on the front position of the car and the MEMS sensor is fitted on the back side of the car. Fig 2.depicts the Accident Module.

When the car on the road gets hit by the opposite vehicle, the car gets tilted. If the car tilts, the MEMS sensor calculates the range and compares with the threshold range. If the calculated Value exceeds a certain range, the accident is detected. The Fig.3 shows the car tilts when the opposite vehicle hits above the range.

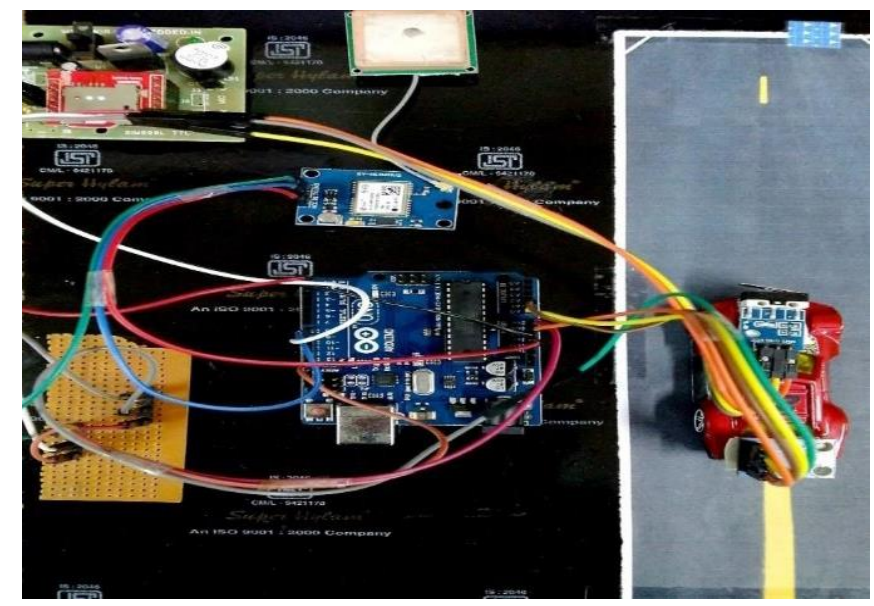

Fig.2 Vehicle Fitted with Sensors 


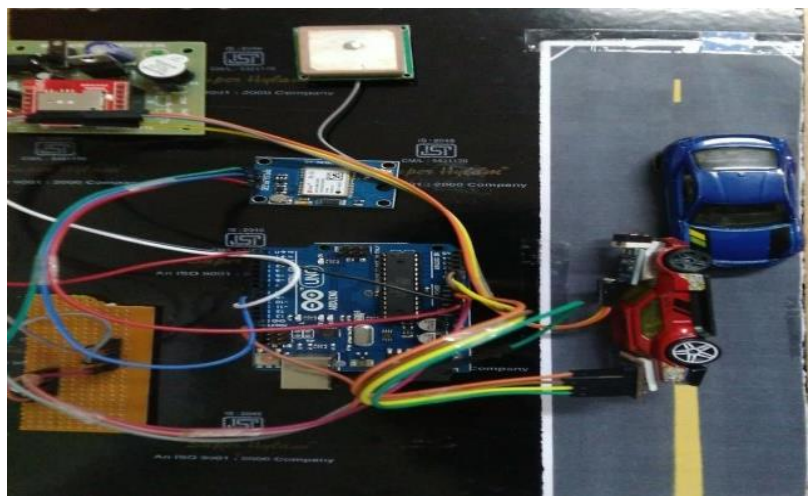

Fig.3 Accident Detection

When the car gets hit by opposite vehicle in a straight line, the car gets crashed. If the car is crashed, it creates an excess pressure and it detects the collision. Therefore, the crashed value changes from 0 to 1 and the accident is detected.

If CRASH $0=$ Accident not Detected.

CRASH 1 = Accident Detected.

When the MEMS Sensor changes with respect to $\mathrm{X}, \mathrm{Y}$ and $\mathrm{Z}$ Values and it exceeds the Threshold range, it is detected as an Accident.

Table-I: Output of Sensor

\begin{tabular}{|l|c|}
\hline \multicolumn{1}{|c|}{ Sensor Value } & \multicolumn{1}{c|}{ Output } \\
\hline $\mathrm{X}=0, \mathrm{Y}=0.225, \mathrm{Z}=0.3$ & Accident not Detected \\
\hline $\mathrm{X}=69.6, \mathrm{Y}=68.4, \mathrm{Z}=60.2$ & Accident Detected \\
\hline $\begin{array}{l}\mathrm{X}=12.5, \mathrm{Y}=55.3, \mathrm{Z}=1.5 \\
\text { and } \\
\text { Crash Sensor=1 }\end{array}$ & Accident Detected \\
\hline
\end{tabular}

Table I shows the MEMS value when the position of the vehicle is changed or it is hit due to the occurrence of accident.

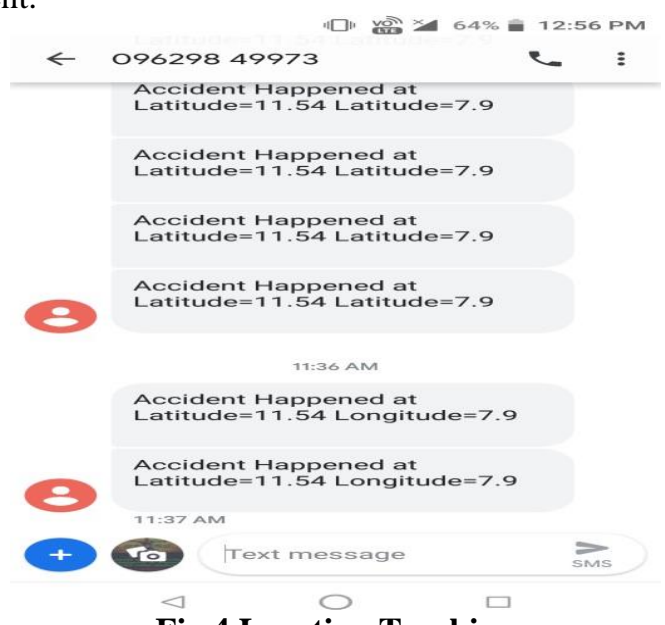

Fig.4 Location Tracking

The latitude and longitude values of the accident location spot are sent to the registered mobile number of the ambulance section using GSM and GPS. The Fig.4 shows the accident zone with latitude and longitude values.
The Fig. 5 represents the Ambulance and Traffic section. The Ambulance unit consists of an RF Transmitter which is used to communicate with an RF receiver on the Traffic section and helps the ambulance to pass the traffic junction.

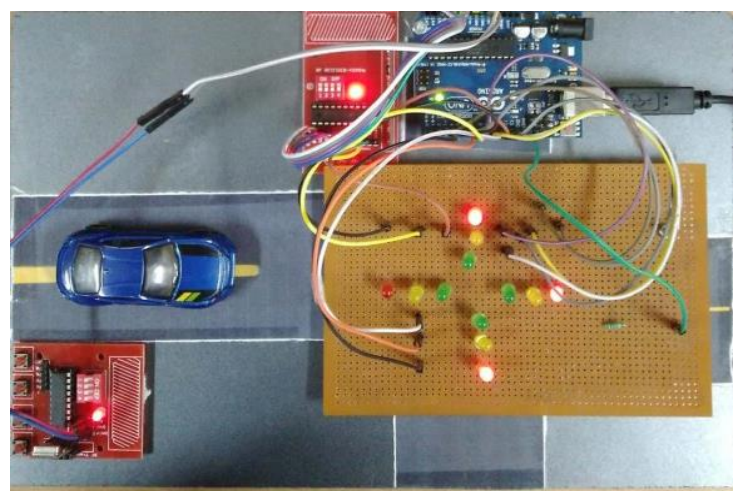

Fig.5 Traffic Section

When the ambulance is nearing the traffic signal, the RF Transmitter will communicate with the RF Receiver 100 metres before the Traffic signal. This helps the ambulance to cross the traffic signal changing the signals from Red to Green without time delay.

\section{CONCLUSION}

In this paper, we have described the design of Automatic Accident Detection and Smart Traffic Control System. It overcomes the disadvantages and provides timely help to save human lives. The proposed system detects the accident and the ambulance is guided to the hospital by managing the traffic signals by the smart traffic management system. The sensors are located on the vehicle to detect the accident and information is sent to ambulance.

When the ambulance arrives in the traffic junction, the RF Transmitter on the ambulance communicates with the RF Receiver on the Traffic section. This allows the ambulance to cross the traffic junction changing the signals from Red to Green. Thus, Accident Detection and Smart Traffic Control System were implemented in an effective way.

\section{REFERENCES}

1. Sadad Mahamud, Maliha Mansur, Md. Saniat Rahman Zishan, (2017) "An Arduino Based Accident Prevention and Identification System for Vehicles", IEEE Region 10 Humanitarian Technology Conference 978-1-5386-2175-2.

2. MengChu Zhou, WenJing Luan, (2016) "A Two-level Traffic Light Control Strategy for Preventing Incident Based Urban Traffic Congestion", IEEE Transactions on Intelligent Transportation Systems, 1524-9050.

3. Dian-liang XIAO, Yu-jia TIAN, "Reliability of Emergency Rescue System on Highway", 2009.

4. XU Guang-hui, Deng Jun, Huang Yong-bo, "The Research and Design of the Control System of the Omnidirectional Self-balancing Intelligent Ambulance", 2011

5. Wei Yan Ma Zhigang, Qiu sihai, "System of Medical Emergency Ambulance for Community based on Zigbee", 2010.

6. Tandrima Chowdhury, Smriti Singh, Dr.S.Maflin Shaby, (2015)" A Rescue System of Advanced Ambulance Using Prioritized Traffic Switching", IEEE Sponsored Second International Conference on Innovation in Information Embedded and Communication Systems, 978-1-4799-6818.

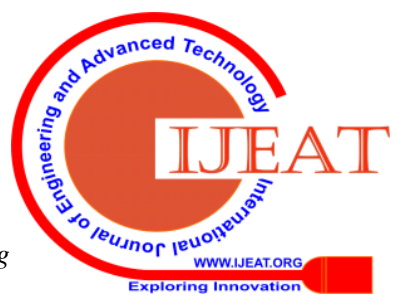


7. "Global status report on road safety 2015", World Health Organization,2016.[Online].Available:http://www.who.int/violen ce_injury_prevention/road_safety_status/2015/en/. (Accessed: 22Mar- 2016)

8. M. Ruikar, "National statistics of road traffic accidents in India", Journal of Orthopedics, Traumatology and Rehabilitation, vol. 6, no. 1, p. 1, 2013.

\section{AUTHORS PROFILE}

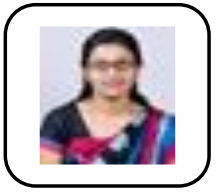

Kokila B is Assistant Professor in the Department of Computer Science and Engineering, Sri Ramakrishna Institute of Technology, Coimbatore. She received B.E degree in Anna University, Coimbatore in the year 2011 and M.E degree in Anna University Chennai in the year 2015. Her area of interest includes data analytics, Internet of Things, Image Processing.

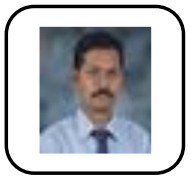

Sathyaseelan K is Assistant Professor in the Department of Information Technology, Sri Ramakrishna Institute of Technology, Coimbatore. He received B.Tech degree in Anna university, Chennai in the year 2007 and M.E degree in Karpagam University, Coimbatore in the year Internet of Things. 2013. His area of interest includes Big Data Analytics,

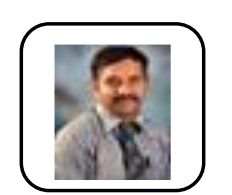

Pradeep C is Assistant Professor (Sr.Gr) in the department of Mathematics and Humanities, Sri Ramakrishna Institute of Technology, Coimbatore. He has received B.Sc and M.Sc degree in Mathematics, Bharathiar University, Coimbatore. He has obtained M.E in System Engineering and Operational Research, Anna University, Chennai. He received his Ph.D in Mathematics from Bharathiar Univerisity, Coimbatore in the year 2019. His research interest includes neural networks, differential equations and data analytics. 